\title{
How Practitioners' Understanding of Dialogical Theory Can Enhance Co- Construction of Meaning and Support the Choice and Control of People Who Have Complex Communication Support Needs
}

\author{
Jacky Smith
}

\begin{abstract}
People who have complex communication support do not have active choice and control in the process of defining how their lives are organised and the support that they receive, despite there being laws and recommendations in place from many bodies such as the United Nations or national governments. The tendency is that the expression of the needs and expectations originate in the opinion of the people closest to the person who has complex communication support needs, rather than from the person themselves. This problem is related to the fact that the dominant model of communication used in this context is based on information transfer and decoding, causing practitioners to regard the need to interpret and negotiate meaning as problematic and somehow differing from other communicative episodes.

This challenge can be met by using a dialogical approach where communication is seen as a process of negotiation where meaning is co-constructed through a sequence of interactions. In situations where practitioners are supported to apply dialogical theory in communication partnerships with people who have complex communication support needs, practitioners' confidence in co-constructing meaning can grow and communication can be richer, supporting direct consultation.

This article seeks to explore and bring together relevant literature on these topics, highlighting the role of the dialogical approach within the context of the international human rights framework.
\end{abstract}




\section{Keywords}

Human Rights, Person Centred Planning, Complex Communication Support Needs, PMLD, Choice and Control, Dialogicality, Increasing Practitioner Confidence. 


\section{Introduction}

The purpose of this article is to explore legislation and policy around person centred planning, to pinpoint current concerns associated with consulting with people who have complex communication support needs, and to explore how thinking about consultation against the backdrop of dialogical theory may support practitioners in the field.

Many countries in Europe, and around the world, have embraced the ethos of 'person centred planning' as the driving philosophy that underpins the support of people who have disabilities. This support can be referred to in many different ways, including independent living', 'person-centred services and 'self-directed support'. However these terms are all based on the same principle: if people with disabilities are to participate and contribute as equal citizens they must have choice and control over the support they need to go about their daily lives. (Joseph Rowntree Foundation 2007). Few would argue with this position. Personcentred supports are based on the individual's interests, preferences and strengths and require active involvement of the focus person and people who are important to him/her (Schwartz, Holburn, \& Jacobson 2000).

However, for those of us who support people who have complex communication support needs, finding out what someone wants from their life, and supporting their active involvement in making choices and excerpting control may be challenging. These challenges are clear in the definitions, The Scottish Government (2011) notes that "People have communication support needs if they need support with understanding, expressing themselves or interacting with others" (p. 5), and Mansell (2010) describes people with Profound and Multiple Learning Disabilities (PMLD), as being among the most individuals with disabilities in the community, haveing a profound intellectual disability, and severely limited understanding. The term PMLD and profound intellectual and multiple disabilities (PIMD) are in general used to describe people who have similar support needs and either term can be used in different settings (Scottish Government, 2013).

Getting this process right is of critical importance to people such as this where communication can be seen as problematic, as it has been argued that where people have more choice and control they are more likely to have a better quality of life (Self Directed Support: A National Strategy for Scotland, 2010).

\section{Human Rights Framework}

There is a clear commitment from society, through human rights legislation, that all people have the right to have their voices heard.

The United Nation Convention on the Rights of Persons with Disabilities (UNCRPD) is an international treaty, ratified by the vast majority of countries across the world (with United States of America being one notable exception). The Scottish Human Rights commission 
describes how the convention deals with issues of choice and control in the following terms, emphasising the importance of supported decision-making;

"People with disabilities have the right to make their own decisions in all areas of life, on the same basis as other people and there are duties to provide the support people need to exercise that capacity. This is an area which continues to develop, with the Committee who monitor the Convention calling for a fundamental move away from decisions being made on behalf of a person whose decision-making ability may be impaired (substitution-decision making) towards greater respect for their will and preference, and more emphasis on supporting them to make decisions, even in tough cases. (Scottish Human Rights Commission, Advocating for Human Rights)

There is a clear acknowledgment here that decision-making may not always be easy or straightforward, but that support must be available in all cases. It would be reasonable to assume that the 'tough cases' alluded to here would encompass the support of people who have complex communication support needs. This mention of supported decision-making as being the goal as opposed to substitute decision-making is an important distinction, and emphasises the importance of direct consultation.

In addition, The European Convention on Human Rights and The United Nations Convention on the Rights of the Child both include articles protecting freedom of expression. These international treaties inform and drive change to the local legislation, policies and guidance that exist in the countries that ratify them. Used effectively, they have the potential to offer us a set of standards that shape policies, programmes and practical interventions, something that concerns us all in our everyday lives.

\section{Person Centred Planning around the World}

Herps, Buntinx, \& Curfs (2016) note that England, The Netherlands, Belgium, and Canada as well as several American States have Person Centred Planning as their policy for social services. Hinz (2011) found Person Centred planning to be the situation (at least to some extent) in Austria, Bosnia-Herzegovina, Croatia, The Czech Republic, Germany, Ireland, Italy, Latvia, Luxemburg, Macedonia, Netherlands, Slovakia, Slovenia, Spain, Sweden, Switzerland and United Kingdom (this study looked at Europe only).

In Scotland, Social Care was reformed in 2014, with the implementation of the Social Care (Self Directed Support) (Scotland) Act 2013, commonly referred to as 'The SDS Act'. Within this legislation is enshrined the belief that people requiring social care services should be afforded greater choice and control over how they receive services and support. Within Government guidance there is specific mention of the importance of direct engagement when people who have communication support needs are being consulted about what they want from their social services (also referred to as their personal outcomes). The guidance explicitly states that; 
Finding out from the individuals themselves what is most important to them in life is central to taking an outcomes approach. Therefore, regardless of how difficult communication is, it is vital to engage directly with the individual concerned rather than relying solely on carers or significant others. (Cook, Walker, Miller, \& Barrie, 2010, p. 5).

This guidance makes it clear that no matter how complex someone's communication support need is, the onus is on the communication partner to find a way of establishing the views of the person, directly with the person, clearly bringing the ethos of the UNCRPD into the centre of local policy.

\section{Current experience of choice and control for people who have communication support needs}

Against the clear legislative background, what then does the literature tell us is the experience of the person being supported? How then, are people who have communication support needs participating in the person centred planning process?

Stalker \& Moscardino (2012) state that it is a challenge for practitioners in the field of social care to engage directly with people who have complex communication support needs, due to the very complexity of that need. Studies have shown that there is little evidence of direct engagement taking place with people who use services and have communication support needs about what support they want (Temple, Lloyd, Preston-Shoot \&Wuu, 1996; Cameron \& Murphy, 2000; O’Sullivan 2001).

Hamm and Mirenda (2006), in a study on post-school quality of life for individuals with complex communication found that "outcomes in important life domains were generally discouraging." A high positive correlation was found between quality of life and quality of communication scores, and "participants who achieved relatively better outcomes showed evidence of higher communicative competence" (p. 134). Baxter, Hart, Reid and Smith (2015), in a study of young people with disabilities leaving school found that "Overall, young people are not consistently involved in agreeing their own personal outcomes, particularly when communication partnerships become more challenging. We cannot, therefore, conclude that their personal outcomes are reflected in the support that is commissioned". Gjermestad (2017) cites a Norwegian report that illustrates the risk of persons with profound intellectual disability being 'invisible' and of their being a 'silent user group'.

The review conducted here of relevant research reports has shown that that for people who have complex communication support needs, the obligation to directly consult when planning services is not always being met. Therefore people with communication support needs are not directly participating in the decision making process. This stark reality implies that, as a society, we are failing to directly engage to identify the goals, dreams and hopes of people who have complex communication support needs. It would seem that as this fundamental building block, this vital direct engagement to 'find out from the individual 
themselves what is most important to them in life' as Cook et al. (2010) state, is missing, then it must follow that it is impossible for the person to have any kind of meaningful participation, choice or control in their care and support. This contravenes both the spirit and the letter of the relevant legislation.

Why is this the case? What then, are the barriers to finding out what people who have communication support needs want for their life? Clearly, given the above definitions, this will not be a straightforward process, and skilled support will be required from a communication partner. However, many people are supported by communication partners who know them well and are attuned to their specific communication. Why is it that peoples voices are still not being heard?

Grove, Bunning, Porter and Olsson (1999) note that when supporting the communication of a person who has PMLD there is a risk that "the meaning assigned to the communication is more likely to reflect the hopes, fears and desires of the interpreter than those of the person with the disability"(p. 190). This notion of what Grove et al. refer to as the 'interpreter' bringing their authentic self to the interaction as a 'risk' to be guarded against, is a concern shared by other in the field. Lewis and Porter (2004) describe how movement and drama have been used to support young people who have PMLD to express views, resulting in researchers having to "face the task of analysing the meaning or message behind the response. They are therefore called on to validate their interpretation." (p. 19). Ware (2004) urges that a drawback of consulting people who have PMLD is that "methods which attempt to ascertain the views of this group are highly inferential" (p. 175). Thus, some researchers in this field have identified that there are risks and problems inherent to situations where the utterances of people who have complex communication support needs require interpretation by the people who support them. This general feeling of 'risk' in the literature; this clear uneasiness and belief that this communication somehow differs from other communication must have an impact on the way that such direct consultation is viewed. If practitioners view this task as something special, requiring additional, specialist skills of interpretation, negotiation and inferring meaning, over and above those needed in everyday communicative episodes, then this must have an impact on the confidence of the practitioner in their interpretations

Others acknowledge this process of interpretation and see the collaboration as a positive. When writing about supporting participation (of children in this case) in decision making, Ulvik argues that "A conceptualisation of participation in which co-construction of meaning is central implies that the professional task, accordingly, will be to engage on the work of meaning production in collaboration with the child." (2015)

So Ulvik (2015) asserts that practitioners, when consulting with young people, must coconstruct meaning together with the young person. Grove et al. (1999) maintain that when supporting someone who has complex communication support needs in decision-making, any 
interpretation of communication is of a provisional and contingent nature. Ulvik seems to view this as a positive process; whereas Grove et al. seem to suggest that there are inherent risks to this. No matter that there are two differing views on the desirability of this process; the description is essentially the same. Here, communication is viewed as a process, where meanings are inferred, which involves collaboration and co-production. This way of regarding consultation and participation chimes with several current theories on communication. The most closely linked of these theories are the theory of dialogicality, as most notably espoused by Ivana Markova (2003) and Per Linell (2009), and the theory of cocreating communication, put forward by Anna Nafstad and Inger Rødbroe (1999).

\section{Dialogism}

Dialogism is a theoretical approach to communication. The primary premise within dialogism is "that humans live in the world of others and that their existence, thought and language are thoroughly interdependent with the existence, thought and language of others" (Markova, Linell, Grossen \& Orvig, 2007, p. 1). Markova (2006) further notes that 'dialogue' can refer to interaction by way of spoken language, bodily communications, pictures, and symbols. Linell (2009) contends that "speakers cannot by themselves determine all aspects of interpretation of their own utterances" (p. 61) thus "utterances and interpretations are coauthored". Markova et al. (2007) argue that no word, sign or symbol can speak to everyone in the same way. Thus, in this theoretical approach, communication is seen as a process of negotiation, with no utterance having explicit meaning without interpretation. Linell (2009) asserts that dialogical theories are concerned with human sense making, in so far as they relate to how human beings make sense of the world, each other and ourselves. Linell (2009) also defines the basic import of dialogicality as "a human being, a person, is interdependent with others experiences, actions, thoughts and utterances; a person is not an autonomous individual who can decide everything for him or her self" (p. 11). Markova (2013) clarifies that "dialogical approaches assume that thought, knowledge and language are generated from interactions between the self and others". This meta-theory can be related back to Ulvik's description of professionals engaging in the work of meaning production and co-construction of meaning with the people that they support (Ulvik, 2015).

\section{Co-creating Communication}

Nafstad and Rødbroe (1999), writing about supporting communication with people who are deafblind found that "communicative interaction emerges in the form of negotiation of shared meaning."(p. 28). They suggest that with a shared sense of being together, communication partners can "create a world of shared experience which gives bases for negotiating shared meanings and shared vocabularies." (p. 19). They further contend that this 'shared world of experience' lays the groundwork for the co-creation of shared meaning. 
The co-creating communication approach has very much been derived from an understanding of the typical development of cognition, communication and learning in children.

So, is there a practical role that an understanding of these theories of communication and cognition can have when consulting with people who have complex communication support needs? Grove et al. (1999) argue that when supporting people who have PMLD, "meaning should be viewed as the negotiated outcome of interactions, always involving inference" (p. 190). This clearly resonates with the theory of dialogicality. Grove et al. are actually describing here all communication as seen from a dialogical perspective, not solely communication partnerships between people who have PMLD and the people who support them. Dialogue theory describes that all communication is a process of inference and negotiation, with myriad influences upon the meaning making. Markova (2006, p. 127) postulates that "dialogue is shaped by participants' concepts and ideas".

\section{Information for Practitioners about dialogical theory}

Hostyn, Daelman, Janssen and Maes (2010) note that research around communication with those who have profound intellectual and multiple disabilities (PIMD) has been dominated by the traditional information-processing approach. Shannon and Weaver (1949), Jakobson (1960), and Saussure (1974), all proffered models that attempted to describe the process of communication. These communication models have in common the premise that an utterance has one meaning, as long as the 'receiver' of the message can 'decode' the 'coded' message they can understand the thought behind the message. In this theory, a message would have one fixed and constant meaning when it left the 'sender'. There is no place in these theories for the influence exerted by the receiver, the environment, the past, or the context of the interaction. These models of communication, which are characterised as transfer or 'pipeline' models, view meanings as fixed. Linell (2009) categorised the transfer model of communication as "intrinsically connected to the idea that language must be a code with relations between stable expressions and stable meanings" (p. 39). Hostyn et al. (2010) note that conversely, from the dialogical approach communication partners simultaneously engage in the process of meaning making, and rather than a transmission of information, communication is a dynamic and creative process. They also note than in settings where people who have PMLD are supported, "dialogical theory is often unknown by practitioners' (p13). It can be argued therefore, that if the traditional view of communication is the prevailing one held by practitioners in the field, then this could contribute to the issues identified by Grove et al. (1999), Lewis and Porter (2004) and Ware (2004), of the practitioner who may be at risk of failing to identify the 'right' meaning behind an utterance. A knowledge of dialogical theory may help to support confidence and attunement in the practitioner. Hostyn et al. (2010) who carried out a study which encouraged a dialogical 
viewpoint amongst practitioners by the introduction of the scale for dialogical meaning making, note that a dialogical viewpoint emphasising the general existence of asymmetry between communication partners makes communications with persons with PIMD less deviant from all human interaction. The literature from the field of supporting people who have PMLD already reflects that meaning is negotiated, and acknowledges asymmetry. However, this is not situated with knowledge of wider dialogical theory, and is seen as somehow separate to other communication episodes. It may be that if practitioners view their communication with people who have complex communication support needs as being fundamentally the same as all other communication, as described in dialogical theory, then some of the issues identified would be alleviated.

\section{What happens when practitioners are supported to think in a dialogical way?}

Gjermestad (2017) describes a study where practitioners who were supporting people who have PMLD were offered support and training, in what she terms 'narrative'. She describes narrative as:

Through narratives, people understand each other's experiences and make them meaningful. Narratives develop from birth and throughout everyday interactions between people, and they are crucial for building and sustaining relationships with others. All people start their narrative development before they are verbal. Narrative can be described as meaning that is communicated and meaning that is interpreted (Andrews et al., 2013).

This description of narrative certainly sounds similar to the way that dialogical theory describes communication. Gjermestad (2017) goes on to describe the implication of this approach as practitioners' recognition that each person deploys distinctive and unique communication methods, which need to be interpreted in the light of the actual situation and context, as well as historical knowledge of the person's expressions and utterances. Gjermestad (2017), when describing the increase of practitioners narrative confidence through training, found that providing arenas for discussion and reflection among staff were effective, as well as providing a forum for sharing various interpretations of the non-verbal and bodily expressions of persons with profound intellectual and multiple disabilities. She found that this "can contribute to a richer understanding of these individuals, and promote and strengthen their fundamental human rights". This supports the study of Smith (2015) that found that focus groups that were set up as an arena to focus on negotiated interpretations of utterances of people who have complex communication support needs increased the confidence of practitioners. In this study, a group of practitioners who worked with people who have complex communication support needs received some training on dialogical theory. These practitioners then formed focus groups which viewed video of communication episodes, between people who have complex communication support needs and practitioners who support them. 
An excerpt of the transcribed footage of the discussion of one of the focus groups is included here in detail as it gives a practical illustration of an example of the application of dialogical theory to the consultation process. It shows how the group participants' knowledge of dialogical theory influenced their interpretation of the episode that they viewed. . The video footage that the group watched was centred on a Talking Mats session with Oliver, who has a communication support need, and Stella who is a practitioner. Talking Mats is an interactive communication tool that uses three sets of picture communication symbols - topics, options and a visual scale - and a textured mat on which to display them. In this case it was being used to elicite Oliver's views on different activities.

The participants are identified by the denotation $F 1$ to $F 11$, and $R$ identifies the researcher.

\section{Theme 1 - Do I look like I cook?}

Stella asks Oliver if he likes preparing meals, and shows him a pictorial symbol depicting someone cooking. He looks straight into her eyes, and gives her a long intense look. There is general laughter from the focus group participants as they watch this sequence.

R: “OK! Did we see any communication there! What happened?"

R: "so we saw, Stella said 'do you like cooking meals' and then...

F1: "withering look"

F8: "the head dropped (drops her head and stares out from under her eyebrows)"

F8: "the hand was thrown up ..."

F11: "I think it was instant dismissal 'you do the cooking"”

F9: "that's curious because he still put it in the yes [Oliver had placed the card on the mat to indicate that he liked doing the cooking] ...I think he was thinking about his Mum, he liked the thought of his mum cooking"

F11: "that's what I thought as well, I think he was thinking of it as 'is it important that my mum cooks me meals, yes, definitely"

R: "you think he reframed that question in his head?"

F11: "yes"

The general discussion in the group here could be summed up in that they felt that Oliver's actions were saying 'Well I don't do the cooking', and he had put the symbol down in the Talking Mat to suggest that he liked his Mum doing the cooking. This might suggest he felt it was clear to all concerned that he did not cook; therefore, he was answering the question in a way that made sense for him. This reinterpretation and negotiation of the question could be explained under the theory of dialogicality, where meaning is negotiated and renegotiated in every setting. Markova (2008) further explains that "word and gestures are always doubly 
orientated, i.e. towards the self and towards the other, they are always open to different interpretations and in this sense they are ambivalent" (p5). This difference of interpretation seems to be evident here.

The focus group continued to discuss the same section of the video;

F7: "the other thing is, could it be that it's what he thinks Stella's expectation of the answer to that question should be? So, he is saying [to himself] 'I think that she thinks that it is important'. He seems a lot more self-conscious there at the end of that question."

The theory if dialogicality describes dialogue, as explained by Markova (2008, p. 25) that "always involves third parties who are not present", as discussed previously. This could suggest that 'Other voices' were involved at this time, the voice of Oliver that thinks he should help out more in the kitchen, the voice of Stella as imagined by Oliver, the voice of his mother who wants to cook for him for instance.

F1: 'I am wondering as well, the proceeding card to cooking was 'home', I am wondering, like there is one thing, and you bring in a second thing... so cooking at home he is thinking of, not cooking here"

R: "so, it's what came before has changed the meaning?"

F7: "there is that way he was talking about the birds at home" [earlier in the conversation].

F1: "so the context of what was being brought forward and discussed, it flows naturally from birds at home, to home, to cooking at home"

The group have discussed an example of sequentiality, as outlined by Linell $(2009, \mathrm{p}$. 186). For him, "sequenitiality means that the situated interpretations of utterances and other acts are partially dependent on their position in sequences of actions". Therefore, when Oliver is described as 'thinking of cooking at home' because the proceeding question had been about 'home', that could be describing as sequentiality.

In this example, if the interaction was analysed using the more traditional transfer model of communication, it would appear that Oliver stated, by means of the Talking Mat, that he likes cooking. However, though applying aspects of dialogical theory, the focus group agree that their interpretation is that: Oliver likes the idea of someone, possibly his Mum, doing the cooking for him; for Oliver cooking happens at home; and that he knows that other people might have the view that he should help out a bit more with cooking. Looking at this communication episode through the lens of dialogicality has given alternative and richer meaning to the utterances. This study illustrates that practitioners with some knowledge of 
dialogical theory can apply in practice this theory in communicative situations to support meaning making. Once this knowledge is embedded and used in practical situations, this process of negotiation where meaning is co-constructed through a sequence of interactions can support the communication partnership.

As a result of taking part in this study, all participants felt that they had become a better communication partner, had developed new skills in supporting people to set outcomes which they would use in their practitioner role, learned something new around communication and increased their confidence in their role.

\section{Conclusion}

Legislation is in place protecting and supporting human rights, and social policy promoting person centred planning reflects and translates these fundamental rights onto the way that people who have disabilities are supported. For people who have complex communication support needs this is not just an abstract process, as it is suggested that where people have more choice and control they are more likely to have a better quality of life (Self Directed Support: A National Strategy for Scotland, 2010). This article has explored the potential that people who have communication support needs are not having their voices heard despite this legislative background. Further literature seems to indicate that there are ingrained concerns and fears around situations where practitioners who support people who have complex communication support needs interpret their utterances. However, an understanding of dialogical theory demonstrates that in fact the interpretation of utterances is fundamental to all communication, and is not restricted to communication partnerships where one partner has complex communication support needs. It is suggested that dialogical theory is not at the moment widely understood by practitioners in the field. An understanding of this theory could support the confidence of practitioners to directly engage with people who have complex communication support needs, thus ensuring that they have more choice and control in their care and support. Gjermestad (2017) has brought the understanding of dialogical theory and the support of the communication partnerships directly back to human rights and the fundamental view that "sharing interpretations of the utterances people who have complex communication support needs can contribute to a richer understanding of these individuals, and promote and strengthen their fundamental human rights." (p1) The importance of getting this process right cannot be over emphasised, as social care "supports people at their most vulnerable, and often covers the most intimate and private aspects of their lives. With choice and control, people's dignity and freedom is protected and their quality of life is enhanced." (Department of Health, 2010, p. 15). 


\section{References}

Baxter, M., Hart, P., Smith, J., \& Reid, J. (2015) Working Together To Make It Happen: helping young people move on successfully SDS Consortium

Cameron, L., \& Murphy, J. (2000). Making Choices at the Time of Transition for Young People with a Learning Disability. AAC Research Unit, Department of Psychology, University of Stirling.

Cook, A., Walker, E., Miller, E., \& Barrie, K. (2010). Improving Communication around Outcomes: A resource to support reflection and practice development, Edinburgh: Joint Improvement Team.

Coupe-O'Kane, J., \& Goldbart, J. (1998). Communication before speech: Development and assessment. London: David Fulton Publishers.

Department of Health, (2009) Personal Health Budgets: First Steps, London, Department of Health.

Gjermestad, A. (2017) Narrative competence in caring encounters with persons with profound intellectual and multiple disabilities. International practice Development Journal, 7,, Suppl, Article 7.

Grove, N., Bunning, K., Porter, J., \& Olsson, C. (1999). See What I Mean: Interpreting the Meaning of Communication by People with Severe and Profound Intellectual Disabilities. Journal of Applied Research in Intellectual Disabilities, 12(3), 190-203.

Hamm, B., \& Mirenda, P. (2006). Post-school quality of life for individuals with developmental disabilities who use AAC. Augmentative and Alternative Communication, 22(2), 134-147.

Herps, A, Buntinx W, Curfs L. (2016) Individual support planning with people with ID in The Netherlands: Official requirements and stakeholders' expectations. ALTER - European Journal of Disability Research / Revue Européenne de Recherche sur le Handicap, 10(4), 281-288.

Hinz, A. (2011). The European Situation on Person Centred Planning- A European Survey in Lunt, J. and Hinz, A. Eds. (2011). Training and practice in person centred planning: A European perspective.

Hostyn, I., Daelman, M., Janssen, M.J. \& Maes, B. (2010). Describing dialogue between persons with profound intellectual and multiple disabilities and direct support staff using the Scale for Dialogical Meaning Making. Journal Intellectual Disabilities Research, 54(8), 67990.

Jakobson R. (1960). Closing Statement: Linguistics and Poetics, in Sebeok, T. (Ed). Style in Language (pp350-377). Cambridge: The MIT Pres.

Joseph Rowntree Foundation, (2007). Person Centred Supports.

Lewis, A., \& Porter, J. (2004). Interviewing children and young people with learning disabilities: guidelines for researchers and multi-professional practice. British Journal of Learning Disabilities, 32(4), 191-197.

Linell, P. (2009). Rethinking language, mind, and world dialogically: Interactional and contextual theories of human sense-making. Charlotte, NC: IAP, Information Age Publishing, INC. 
Lloyd, M., Preston-Shoot, M., Temple, B., \& Wuu, R. (1996). Whose Project is it Anyway? Sharing and shaping the research and development agenda. Disability and Society, 11(3), 301-316.

Mansell, J. (2010). Raising our sights: services for adults with profound intellectual and multiple disabilities, University of Kent retrieved from https://kar.kent.ac.uk/24356/ 1/DH_2010_Raising_our_sights.pdf

Markova, I. (2003). Dialogicality and social representations: The dynamics of mind. Cambridge: Cambridge University Press.

Markova, I. (2006). On 'the inner alter' in dialogue. International Journal for Dialogical Science. 1(1), 125-147.

Markova, I., Linell, P., Grossen, M., \& Orvig, S. A. (2007). Dialogue in Focus Groups: Exploring Socially Shared Knowledge. London: Equinox Pub.

Markova, I. (2008). Dialogicality. Presentation at DbI Communication Network conference Co-creating Communication with Persons with Congenital Deafblindness, October 8-11 2008, Leeds, UK. Retrieved from www.sense.org.uk.

Markova, I. (2013). On dialogue and dialogicality. Network of Dialogical Practices. Retrieved from Practice shttp://www.opendialogicalpractices.eu/interview-with-ivana-markova/

Nafstad, A., \& Rødbroe, I. (1999). Co-creating communication: Perspectives on diagnostic education for individuals who are congenitally deafblind and individuals whose impairments may have similar effects. Dronninglund: Forlaget Nord-Press.

O'Sullivan, T. (2001). Young Adults Transition Project: Draft Summary. London: Optimum Health Services NHS Trust.

Saussure, F. (1974). Course in general linguistics. London: Peter Owen.

Schwartz, A. A., Holburn, S. C., \& Jacobson, J. W. (2000). Defining person centeredness: Results of two consensus methods. Education and Training in Mental Retardation and Developmental Disabilities, 35(3), 235-249.

Scottish Government (2010). Self Directed Support: A National Strategy for Scotland. Edinburgh: Scottish Government.

Scottish Government (2011). Principle of Inclusive Communication, An information and selfassessment tool for public authorities. Edinburgh: Scottish Government.

Scottish Government (2013). The keys to Life: Improving quality of life for people with learning disability. Edinburgh: Scottish Government.

Scottish Human Rights Commission, (2017). Advocating for Human Rights

Self Directed Support Scotland (2014). Self Directed Support: Practitioners' guide. Edinburgh: Self Directed Support Scotland.

Shannon, C. E., \& Weaver, W. (1949). The mathematical theory of communication. Urbana: University of Illinois Press.

Smith, J., (2015) Identifying How Focus Groups Utilise Theories of Communication and Cognition to Assist in Determining the Personal Outcomes That are Important to Young People who have Complex Communication Support Needs. (Master's thesis), University of Groningen, Groningen, The Netherlands

Stalker, K., \& Moscardini, L. (2015). A critical review and analysis of current research and policy relating to disabled children and young people in Scotland. A report to Scotland's Commissioner for Children and Young People. University of Strathclyde: Glasgow. 
Temple, B., Lloyd, M., Preston-Shoot, M., \& Wuu, R. (1996). Combining methods, constructing needs and consulting service users: reflections on a research project. Health and Social Care in the Community, 4(5), 300-302.

Ulvik, O. S. (2015). Talking with children: Professional conversations in a participation perspective. Qualitative Social Work, 14, 2, 193-208.

Ware, J. (2004). Ascertaining the views of people with profound and multiple learning disabilities. British Journal of Learning Disabilities, 32(4), 175-179.

Jacky Smith, MSc., Communication Development Practitioner, Sense Scotland, Touchbase, 43 Middlesex Street, Glasgow, Scotland; e-mail: $<j s m i t h @ s e n s e s c o t l a n d . o r g . u k>$. 